\title{
CARACTERIZAÇÃO OVARIANA E DEFINIÇÃO DO NÚMERO DE GERAÇÕES DE MOSCA-DAS-FRUTAS SUL-AMERICANA DURANTE O CICLO DAS CULTURAS EM DOIS POMARES NA REGIÃO DE PORTO ALEGRE, RS, BRASIL
}

\author{
C.P. Reyes, S.M. Jahnke, L.R. Redaelli
}

Universidade Federal do Rio Grande do Sul, Faculdade de Agronomia, Av. Bento Gonçalves, 7712, Porto Alegre, RS, Brasil. E-mail: carolinepreyes@gmail.com

\section{RESUMO}

A mosca-das-frutas sul-americana, Anastrepha fraterculus (Wiedemann, 1830) (Diptera: Tephritidae), é a principal praga das frutíferas no Sul do Brasil. Este trabalho buscou caracterizar as populações de moscas-das-frutas desta espécie capturadas em armadilhas com atrativos alimentares, através da comparação do estágio de maturação dos órgãos reprodutivos de fêmeas de campo e de laboratório. Realizaram-se coletas em dois pomares, um de pessegueiro, com manejo convencional e um de goiabeira, sem manejo, durante uma safra, com dois diferentes atrativos alimentares, em diferentes fases das culturas. Foram utilizadas armadilhas do tipo McPhail com suco de uva a $25 \%$ e proteína hidrolisada a $5 \%$. As fêmeas coletadas foram dissecadas, seus ovários medidos em largura e comprimento e foi determinado o grau de maturação sexual, assim com as de laboratório, com a idade controlada. Foram capturadas 895 fêmeas de $A$. fraterculus no pomar de goiabeiras e 139 no de pessegueiros. Determinaram-se três estágios fisiológicos das fêmeas a partir da diferenciação celular dos ovários: imaturas, em desenvolvimento e maduras. Fêmeas maduras de laboratório apresentaram ovários significativamente menores que as de campo. No pomar de pessegueiros identificaram-se, através dos picos de coletas de moscas imaturas, três gerações durante o ciclo da cultura, até a colheita. Nas goiabeiras, o maior pico populacional de moscas imaturas ocorreu no final do ciclo, indicando uma população apta a colonizar outras frutíferas.

PALAVRAS-CHAVE: Anastrepha, ovário, reprodução.

\begin{abstract}
OVARIAN CHARACTERIZATION AND DEFINITION OF THE NUMBER OF GENERATIONSOF SOUTH AMERICAN FRUIT FLIES DURING THE CROP CYCLE IN TWOORCHARDS IN THE REGION OF PORTO ALEGRE, STATE OF RIO GRANDE DO SUL, BRASIL. The South American fruit fly, Anastrepha fraterculus (Wiedemann, 1830) (Diptera: Tephritidae) is a major pest of fruit trees in southern Brazil. This study aimed to characterize the populations of fruit flies captured in traps with food baits, through the characterization of reproductive organs of females compared with females of the laboratory strain. Collections were performed in two orchards; the first, peach trees with conventional management; the second, guava trees without management; during a crop cycle. McPhail traps were used with grape juice at $25 \%$ and hydrolyzed protein at $5 \%$. Collected females were dissected; their ovaries were measured in width and length, and the degree of sexual maturation was determined. Females maintained in the laboratory, with age controlled, were also dissected to serve as a comparison to the field specimens. A total of 895 females of $A$. fraterculus were captured in the orchard of guava and 139 in peach trees. Three physiological stages of the females from the ovarian cell differentiation were determined: immature, in development and mature. Ovaries from mature laboratory females were significantly smaller than those from the field. In the peach orchard, through the peaks of immature flies, three generations were identified during the crop cycle, until the harvest. In guava, the population peak of immature flies occurred at the end of the cycle, indicating that the population was able to colonize other fruit.
\end{abstract}

KEY WORDS: Anastrepha, ovary, reproduction.

Programa de Pós-Graduação em Fitotecnia. 


\section{INTRODUÇÃO}

A praga mais importante da grande maioria das frutíferas exploradas nos estados do Rio Grande do Sul, Santa Catarina e Paraná é a mosca-das-frutas sulamericana, Anastrepha fraterculus (Wiedemann, 1830) (Diptera: Tephritidae) (SALLES, 1998a), compondo de 95 a 97\% das espécies capturadas em armadilhas de monitoramento nessas regiões. Mesmo os melhores materiais genéticos estão sujeitos ao ataque dessa espécie-praga, podendo resultar em grandes prejuízos às culturas (SouzA et al., 2003).

$\mathrm{Na}$ natureza, a longevidade de $A$. fraterculus ainda não foi determinada. Todavia, em temperatura de $25^{\circ} \mathrm{C}$, com $70-80 \%$ de umidade relativa, 16 horas de fotofase e alimentados com dieta artificial à base de gérmen de trigo e levedo de cerveja, a longevidade máxima para fêmeas e machos foi de 161 dias (SALLeS, 2000). De acordo com SALLEs (1993), o fotoperíodo não influi diretamente na duração do ciclo de vida, posturas, fecundidade ou emergência de A. fraterculus. A ocorrência das moscas-das-frutas está associada ao aumento da temperatura ambiente e com a maturação dos frutos de plantas hospedeiras silvestres, os quais influenciam diretamente o aumento da população (BотTON et al., 2005).

A ampla distribuição de espécies de Tephritidae, bem como sua grandecapacidadeadaptativa ecolonizadora, possivelmente está relacionada ao potencial reprodutivo destes organismos (MORGANTE, 1991). A análise deste potencial engloba a investigação de um conjunto de características morfológicas e comportamentais reprodutivas de machos e fêmeas. Isto faz com que a análise estrutural do trato reprodutivo seja fundamental, pois está intimamente relacionada com outras características biológicas, como a idade e o conjunto genético populacional (CRUZ et al., 2000).

TAUfER et al. (2000) estabeleceram a relação entre o amadurecimento ovariano e a longevidade de fêmeas de $A$. fraterculus com temperaturas médias sazonais da região deSão Joaquim, RS, e observaram que quanto maior a idade e a temperatura, maior o número de oócitos amadurecidos nos ovários. Porém, em temperaturas de $9 \mathrm{e} 13^{\circ} \mathrm{C}$, os insetos não mostraram maturação ovariana, apresentando, entretanto, maior longevidade, indicando assim, a ocorrência de mecanismos regulatórios da biologia de $A$. fraterculus que podem auxiliar na sobrevivência dos indivíduos. Sendo assim, os insetos podem estar presentes nos pomares nas estações frias, porém não estando aptos à reprodução. Estudos como esse são necessários e oportunos para a melhor definição de épocas de controle da mosca-das-frutas sul-americana, visto sua real importância como praga de frutíferas.

O presente trabalho teve por objetivo caracterizar a maturação ovariana de fêmeas capturadas em armadilhas a campo em comparação a de fêmeas de laboratório, determinar o número de gerações a campo, durante o ciclo das culturas, a partir do desenvolvimento ovariano das mesmas e definir se ocorre diferença na captura em relação a dois atrativos alimentares.

\section{MATERIAL E MÉTODOS}

O trabalho foi conduzido em dois pomares, um de pessegueiros e outro de goiabeiras. A cultura do pessegueiro, Prunuspersica (L.) Batsch, écaracterística na região de Porto Alegre e predominantemente manejada de forma convencional. Por outro lado, a goiabeira, Psidium guajava L., embora não existam grandes pomares comerciais na região, é uma espécie espontânea e conhecidamente hospedeira de mosca-das-frutas.

Opomar de pessegueiros, conduzido com manejo convencional, localiza-se na área rural do Município de Porto Alegre, RS, Brasil, ( $\left.30^{\circ} 08^{\prime \prime} \mathrm{S}, 5^{\circ} 11^{\prime} \mathrm{O}\right)$, com cinco anos de idade, é composto pelos cultivares, BR3, San Pedro e Premier, totalizando 300 árvores, com espaçamento de 4,5X2 m. Foram instaladas 10 armadilhas do tipo McPhail com $250 \mathrm{~mL}$ de atrativo alimentar, sendo cinco com proteína hidrolisada a $5 \%$ (Bioanastrefa ${ }^{\circledR}$ ) e cinco com suco de uva a 25\% (Suco Concentrado Natural Jota Pê ${ }^{\circledR}$ ) a uma altura de 1,5 $\mathrm{m}$, distribuídas de forma equidistantes, no pomar.

O pomar de goiabeiras não recebeu nenhum tipo de manejo e localiza-se no Centro Agrícola Demonstrativo (CAD), pertencente à prefeitura de Porto Alegre $\left(30^{\circ} 07^{\prime} \mathrm{S}, 51^{\circ} 05^{\prime \prime} \mathrm{O}\right)$. É composto por 30 goiabeiras da cultivar Paluma, num espaçamento de $7 \times 4 \mathrm{~m}$. Neste, foram instaladas quatro armadilhas com cada um dos dois atrativos alimentares distribuídas de forma equidistante no pomar.

As coletas, no pomar de pessegueiros, foram semanais, de 21/10/2009 a 23/12/2009. Em cada ocasião, as armadilhas permaneciam por 48 horas para evitar a decomposição dos organismos. Os insetos capturados eram armazenados em álcool $70 \%$, sendo registrados a data de coleta e o tipo de atrativo e levados ao Laboratório de Biologia, Ecologia e Controle Biológico de Insetos (Biecolab), da Universidade Federal do Rio Grande do Sul, para identificação. No pomar de goiabeiras, as coletas ocorreram de 13/1/2010 a 14/4/2010.

Foi utilizada uma criação artificial de $A$. fraterculus, na qual se conhecia a idade (em dias) das fêmeas para a identificação das idades fisiológicas (períodos de maturação ovariana), tornando possível a comparação com as de fêmeas de campo. Essa criação foi estabelecida com pupas de $A$. fraterculus obtidas de frutos de mirtáceas coletados no Vale do Rio Caí, RS, e foi mantida conforme a metodologia adaptada de SALLES (1992) e JALDO et al. (2001) em sala climatizada 
( $25 \pm 2^{\circ} \mathrm{C}, 70 \pm 10 \%$ U.R., fotofase de 14 horas). Os adultos eram mantidos em gaiolas de madeira com dimensões de $45 \times 30 \times 30 \mathrm{~cm}$, com as laterais cobertas com tecido do tipo voile. Nestas gaiolas eram disponibilizadas água e dieta, constituída de açúcar cristal, levedo de cerveja, gérmen de trigo e extrato de soja (na proporção 3:1:1:1) e complexo vitamínico (Diarium ${ }^{\circledR}$-VitaminLife), sendo um comprimido macerado para cada $250 \mathrm{~g}$ de dieta.

Dez dias após a emergência, eram oferecidos frutos de mamão papaia (Carica papaya Linn.) 'Caliman' como substrato para oviposição. Os frutos eram mantidos nas gaiolas por 48 horase, em seguida, enrolados em papel-toalha, mantidos em recipientes com areia esterilizada, cobertos com tecido voile, e acomodados por 12 dias em câmara climatizada a fim de que as larvas de último instar se deslocassem do fruto para a areia, para empupar. Após esse período, a areia esterilizada era peneirada e os pupários que forneciam a nova geração de moscas da criação artificial eram recolhidos e depositados nas gaiolas para emergência. Diariamente, machos e fêmeas, na mesma proporção, recém-emergidos, eram agrupados em gaiolas com água e alimento, mantidos em câmara climatizada até completarem a idade estabelecida para dissecação. Dez fêmeas de $A$. fraterculus de cada uma das idades (24 horas, cinco, 10, 20, 30 e 40 dias) foram mortas em vapores de acetato de etila e armazenadas em álcool 70\%. A avaliação dos ovários foi feita utilizando fêmeas da terceira geração de laboratório.

As dissecações, tanto das fêmeas com idade controlada, quanto das coletadas nas armadilhas, eram feitas em uma placa de parafina com solução fisiológica. Os ovários eram retirados, depositados sobre uma lâmina temporária de microscopia e medidos nos pontos de maior comprimento e largura com uma lente micrométrica ao microscópio estereoscópico.

Ambos ovários, de todas as fêmeas, depois de medidos foram cobertos com lamínula e levados ao microscópio com aumento de 100x para a avaliação da diferenciação celular e classificação, de acordo com TAufer et al. (2000), adaptada de Pritchard (1970), como: ovário imaturo, presença de oogônias e ausência de oócitos; ovário em desenvolvimento, presença de oogônias, oócitos de primeira ordem e ausência de oócitos corionados; e, ovário maduro, presença de oogônia, oócito de primeira ordem e oócitos corionados. Compararam-se o tamanho dos ovários entre as fêmeas de laboratório e as capturadas a campo e a maturação fisiológica em relação às diferentes idades.

Nas avaliações da maturação ovariana das fêmeas coletadas a campo foram considerados: data de coleta, fase de desenvolvimento dos frutos, a face do pomar e o atrativo alimentar.
Os valores foram submetidos à análise de variância através do teste Kruskal-Wallis e a comparação múltipla pelo teste de Dunn com 5\% de probabilidade, através do software Bioestat 5.0 (Ayres et al., 2006).

\section{RESULTADOS E DISCUSSÃO}

No pomar de pessegueiros foram capturadas 234 moscas-das-frutas, 139 fêmeas e 95 machos, todas identificadas como $A$. fraterculus, conforme chave proposta por ZUCCHI (2000). Nas goiabeiras, foram capturados1.519indivíduos também de A. fraterculus, sendo 895 fêmeas e 624 machos. LeAl et al. (2009), em levantamento realizado em cinco municípios do nortee nordeste fluminense, em pomares comerciais de goiabeiras do mesmo cultivar do presente estudo, também detectaram, em armadilhas McPhail com proteína hidrolisada, $A$. fraterculus como a espécie demosca-das-frutas mais abundante. A dominância desta espécie, dentre os Tephritidae, em pomares e frutíferas nativas no Rio Grande doSul, já havia sido constatada por KOVALESKI et al. (1999) em macieira, Silva et al. (2006) em citros e Gattelli et al. (2008) em mirtáceas ecitros. PEREIRA-RÊGO et al. (2011) da mesma forma registraram exclusivamente $A$. fraterculus, coletando frutos em mirtáceas na mesma região do presente estudo.

A partir da dissecação das 1.034 fêmeas, observou-se que o sistema reprodutivo de $A$. fraterculus é composto por um par de ovários do tipo politrófico, cada um com 20 a 24 ovaríolos; um par de ovidutos laterais; um oviduto comum; uma câmara genital e três espermatecas. As observações feitas no presente estudo corroboram as de MARTINEZ; OrTIZ (1997) e BARTOLUCCI et al. (2006). Segundo PRITCHARD (1970), a presença de três espermatecas em Tephritidae é característica nas espécies dos gêneros Anastrepha $e$ Ragoletis, sendo estes considerados gêneros mais derivados, enquanto que nas de Ceratitis e de outros gêneros ocorrem somente duas. A espermateca é um órgão dearmazenamento de esperma e manter múltiplos órgãos desse tipo permite às fêmeas manipular os ejaculados, fazendo uma seleção espermática póscopulatória para uma maior eficiência de fertilização de óvulos (TAYLOR; YUVAL, 1999).

Foram determinados, a partir da dissecação de fêmeas de laboratório, três estágios de desenvolvimento ovariano. O ovário imaturo caracterizou-se pela ausência de oócitos em desenvolvimento, células nutrizes não visíveis e ovaríolos pouco visíveis (Fig. 1A). O ovário considerado em desenvolvimento apresentou oogônias, oócitos de primeira ordem e ausência de oócitos corionados, neste os ovaríolos já eram visíveis (Fig. 1B). No ovário maduro, foram observadas oogônias, oócitos de primeira ordem 
e oócitos corionados (Fig. 1C). Observou-se neste estudo que há apenas um oócito corionado por vez, pronto para ser fecundado em cada ovaríolo. Segundo WiLLIAMSON (1989), em uma fêmea madura sexualmente, o ovárioéformado por vários ovaríolos, cada um contendo uma série linear e progressiva de oócitos em desenvolvimento, com um oócito maduro distalmente. PRITCHARD (1970), estudando o tefritídeo Dacus tryoni (Froggatt), observou a mesma característica. Assim, a presença de oócitos corionados nos ovaríolos foi tomada como indicativo de maturação sexual no presente estudo.

Com base nos critérios estabelecidos com a dissecação das fêmeas de laboratório, verificou-se que todas, entre 24 horas e cinco dias de idade, encontravam-se em estágio imaturo. Aos dez dias, $70 \%$ das fêmeas apresentavam ovários em desenvolvimento e aos 20 dias, 90\% tinham a mesma condição. Aos 30 dias, $80 \%$ delas estavam maduras e, aos 40 dias, $50 \%$ das fêmeas dissecadas estavam maduras e outras 50\%, em desenvolvimento. Os resultados obtidos corroboram os de BARTOLUCCI et al. (2006), os quais referiram que a maturação ovariana não é uniforme e que é possível encontrar fêmeas da mesma idade com diferentes graus de maturação. MARTinEZ etal. (1995) observaram que em A. serpentina, sob condições de $24^{\circ}$ C e U.R. $70 \%$, a maturação dos ovários ocorre cerca de 14 dias após a emergência, sendo, portanto, mais precoce que em A. fraterculus, mesmo em temperatura média inferior a do presente estudo. PRITCHARD (1970) alertou para o fato de que uma fêmea madura, se capturada num intervalo entre a oviposição e a maturação dos próximos oócitos, pode ser confundida com uma fêmea em desenvolvimento, o que também não pôde ser discriminado no presente experimento, já que nesses intervalos há apenas oócitos de primeira ordem nos ovários e nenhum oócito corionado.
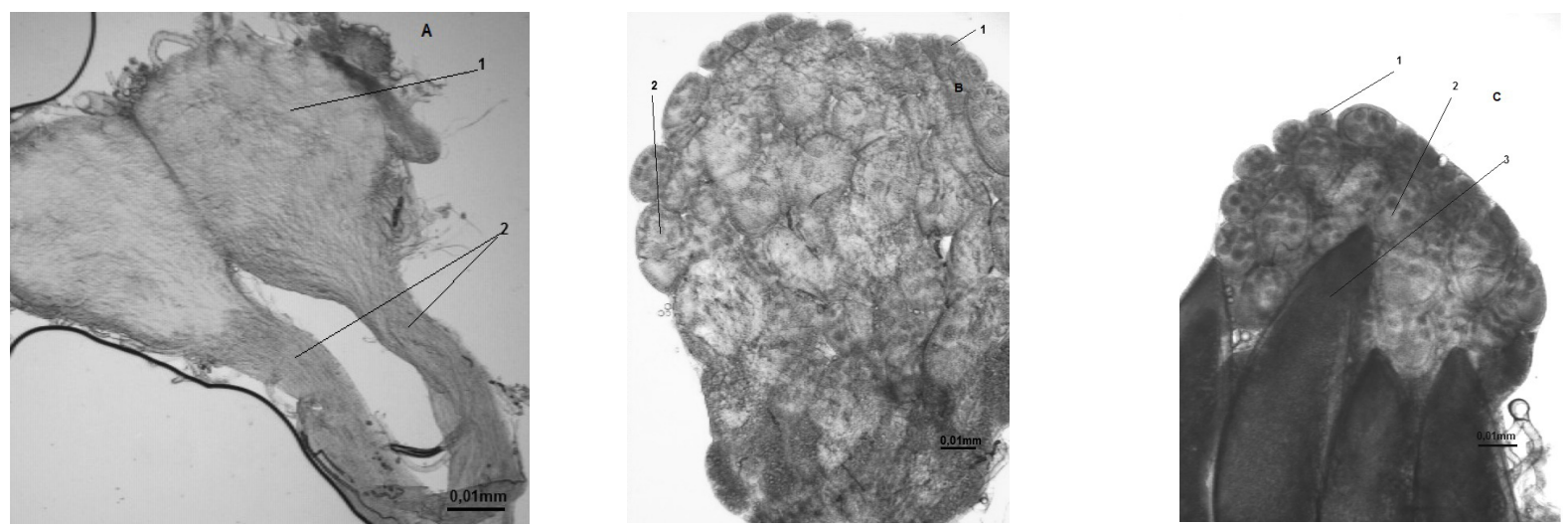

Fig. 1 - Ovários de Anastrepha fraterculus criadas em laboratório: (A) Ovário imaturo (1. Oogônias; 2. Oviduto lateral); (B) Ovário em desenvolvimento (1. Oogônia. 2. Oócito de primeira ordem, com presença das células nutrizes e célula germinativa) (C) Ovário maduro (1. Oogônia. 2. Oócito de primeira ordem, com células nutrizes. 3. Oócito corionado).

A

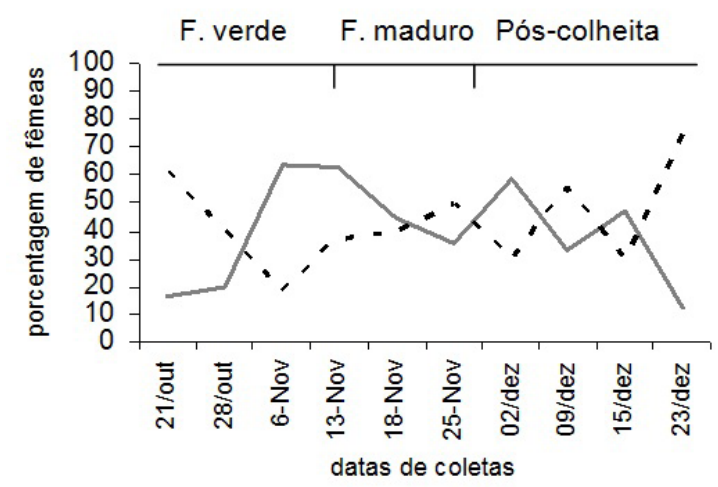

B

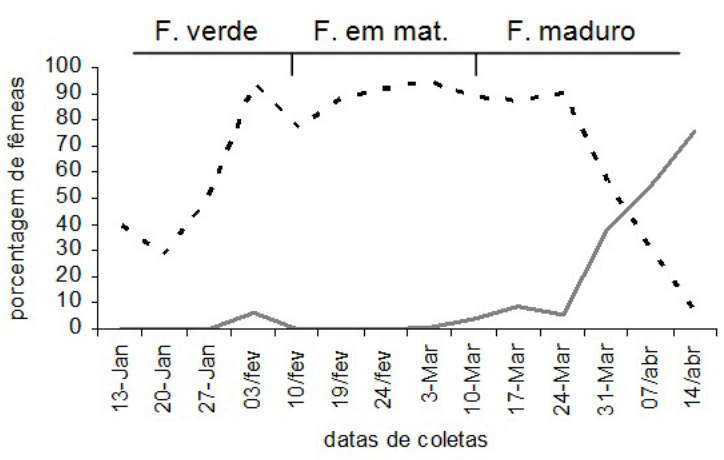

_Fêmeas imaturas _ _ _ Fêmeas maduras

Fêmeas imaturas

- - - Fêmeas maduras

Fig. 2 - Percentagem de fêmeas imaturas e maduras de Anastrepha fraterculus nas diferentes ocasiões de amostragem nos pomares de (A) pessegueiro e, (B) goiabeira (Porto Alegre, RS). 
Em relação ao tamanho dos ovários (Tabela 1), não se constatou diferença significativa entre as medidas de largura e comprimento dos ovários direito e esquerdo, em nenhuma categoria de maturação, nas fêmeas criadas em laboratório, o que foi também observado por PRITCHARD (1970), para D. tryoni. As medidas ovarianas de fêmeas maduras e em desenvolvimento, de laboratório, diferiram entre si e são significativamente maiores do que as de imaturas $(\mathrm{H}$ $=39,94 ; \mathrm{gl}=2 ; \mathrm{P}<0,05)$ para comprimento, e $(\mathrm{H}=$ $52,06 ; \mathrm{gl}=2 ; \mathrm{P}<0,05)$, para largura. Como a variação no tamanho dos ovários está relacionada diretamente ao número de ovaríolos presentes (BRESSAN, 1996) e ao estágio de desenvolvimento das células reprodutivas, as diferenças registradas eram esperadas.

Entre as moscas capturadas nas armadilhas, também não se verificou diferença entre as medidas de comprimento e largura dos ovários direito e esquerdo de fêmeas maduras $(\mathrm{H}=0,1361 ; \mathrm{gl}=1$; $\mathrm{P}>0,05$, para largura e $\mathrm{H}=0,0305 ; \mathrm{gl}=1 ; \mathrm{P}>0,05$ para o comprimento), assim optou-se por apresentar somente os dados de largura do ovário esquerdo.

Para moscas imaturas, a largura média dos ovários daquelas capturadas nas armadilhas com suco e proteína, no pomar de pessegueiros, não foi significativamente diferente das de moscas imaturas criadas em laboratório $(\mathrm{H}=1,33 ; \mathrm{gl}=2 ; \mathrm{P}>0,05)($ Tabela 2). As capturadas no pomar de goiabeiras, com proteína, apresentaram larguras significativamente menores que as de laboratório $(\mathrm{H}=4,017 ; \mathrm{gl}=1 ; \mathrm{P}$ $<0,05)$ (Tabela 2).

Fêmeas em desenvolvimento capturadas em armadilhas com ambos os atrativos, no pomar de pessegueiros, evidenciaram ovários significativamente mais largos que as de laboratório, $(\mathrm{H}=15,2$; $\mathrm{gl}=2 ; \mathrm{P}<0,05)$ não diferindo, entretanto, das do pomar de goiabeiras $(\mathrm{H}=1,97 ; \mathrm{gl}=2 ; \mathrm{P}>0,05)$.

Os ovários de moscas maduras capturadas com os dois atrativos, em ambos os pomares, foram significativamente maiores do que o das maduras originadas no laboratório $(\mathrm{H}=26,04$; $\mathrm{gl}=4 ; \mathrm{P}<0,05)$. Esses resultados revelam que as moscas maduras encontradas na natureza possuíam, em média, ovários maiores que as criadas em laboratório, por três gerações, com a metodologia adotada.

Nas armadilhas com suco, em ambos os pomares, registrou-se diferença entre fêmeas em desenvolvimento $(\mathrm{H}=7,38 ; \mathrm{gl}=1 ; \mathrm{P}<0,05)$ e maduras $(\mathrm{H}=21,08$; $\mathrm{gl}=1 ; \mathrm{P}<0,05)$, sendo a média dos ovários significativamente maior nas capturadas em pessegueiros. Nas armadilhas com proteína hidrolisada, essa medida, em fêmeas de todos os graus de maturação, capturadas no pomar de pessegueiros, foi maior que nas do de goiabeiras (imaturas, $\mathrm{H}=7,32 ; \mathrm{gl}=1$; $\mathrm{P}<0,05$; em desenvolvimento, $\mathrm{H}=4,11 ; \mathrm{gl}=1$; $\mathrm{P}<0,05$ e maduras, $\mathrm{H}=26,9 ; \mathrm{gl}=1 ; \mathrm{P}<0,05)$. Essa diferença pode ter se dado em função de uma maior abundância de nutrientes no pomar de pessegueiros, pressão de seleção maior nesse ambiente ou mesmo uma variação subespecífica dentro da espécie $A$. fraterculus nesse local. O "complexo fraterculus" é citado por SALLES (1995) e, embora não esteja completamente conhecido, poderia esclarecer as diferenças entre tamanhos nas populações da mesma espécie nos diferentes pomares.

Tabela 1 - Médias ( \pm EP) (cm) da largura e do comprimento dos ovários esquerdo (OE) e direito (OD) de Anastrepha fraterculus, em três graus de desenvolvimento, criadas em laboratório.

\begin{tabular}{|c|c|c|c|c|}
\hline \multirow{2}{*}{ Grau } & \multicolumn{2}{|c|}{ Largura } & \multicolumn{2}{|c|}{ Comprimento } \\
\hline & $\mathrm{OE}$ & $\mathrm{OD}$ & $\mathrm{OE}$ & $\mathrm{OD}$ \\
\hline Imaturas & $0,04 \pm 0,002 \mathrm{aA}^{*}$ & $0,03 \pm 0,001 \mathrm{aA}$ & $0,04 \pm 0,001 \mathrm{aA}$ & $0,04 \pm 0,002 \mathrm{aA}$ \\
\hline Em desenvolvimento & $0,05 \pm 0,002 \mathrm{aB}$ & $0,05 \pm 0,001 \mathrm{aB}$ & $0,07 \pm 0,004 \mathrm{aB}$ & $0,07 \pm 0,003 \mathrm{aB}$ \\
\hline Maduras & $0,07 \pm 0,004 \mathrm{aC}$ & $0,07 \pm 0,004 \mathrm{aC}$ & $0,16 \pm 0,005 \mathrm{aC}$ & $0,16 \pm 0,006 \mathrm{aC}$ \\
\hline
\end{tabular}

*Médias seguidas da mesma letra minúscula, na linha, comparam a largura e o comprimento entre os ovários e mesma letra maiúscula na coluna, entre graus de desenvolvimento, não difere estatisticamente pelo teste de Dunn a $(\mathrm{P}>0,05)$.

Tabela 2 - Médias ( \pm EP) $(\mathrm{cm})$ da largura dos ovários de Anastrepha fraterculus nos graus de maturação, criadas em laboratório, e capturadas nos pomares de pessegueiros e goiabeiras, com diferentes atrativos.

\begin{tabular}{lccccc}
\hline \multirow{2}{*}{ Grau } & \multicolumn{4}{c}{ Largura dos ovários } \\
\cline { 2 - 3 } \cline { 5 - 6 } & \multicolumn{2}{c}{ Pessegueiros } & \multicolumn{2}{c}{ Goiabeiras } \\
\cline { 2 - 3 } & $0,04 \pm 0,004 \mathrm{a}^{*} \mathrm{~A}^{* *}$ & $0,04 \pm 0,003 \mathrm{aA}$ & & $0,03 \pm 0,001 \mathrm{bB}$ & $0,04 \pm 0,001 \mathrm{aA}$ \\
\hline Imatura & $0,08 \pm 0,009 \mathrm{aA}$ & $0,09 \pm 0,009 \mathrm{aA}$ & & $0,05 \pm 0,002 \mathrm{aB}$ & $0,05 \pm 0,007 \mathrm{aB}$ \\
Desenvolvimento & $0,12 \pm 0,006 \mathrm{Aa}$ & $0,12 \pm 0,001 \mathrm{aA}$ & & $0,09 \pm 0,001 \mathrm{aB}$ & $0,08 \pm 0,001 \mathrm{Bb}$ \\
Madura & & & & &
\end{tabular}

${ }^{*}$ Médias seguidas da mesma letra minúscula, na linha, comparam atrativos dentro da frutífera e não diferem pelo teste de Dunn $(\mathrm{P}>0,05)$.

**Médias seguidas da mesma letra maiúscula, na linha, comparam o mesmo atrativo entre as frutíferas e não diferem pelo teste de Dunn $(\mathrm{P}>0,05)$. 
O tamanho médio do ovário, menor em fêmeas de laboratório em relação àquelas capturadas nos pomares, especialmente no de pessegueiros, pode ser devido a condições não ideais da criação artificial. Embora a dieta de adultos oferecida seja protocolada (JALDO et al., 2001), é possível que, em ambiente natural, as moscas encontrem uma diversidade maior de substâncias primárias e secundárias para compor sua dieta, o que pode aumentar a performance reprodutiva.

De acordo com Zucoloto (2000), a maioria dos tefritídeos requer nutrientes que são fornecidos pela dieta artificial de laboratório, como: água, carboidratos (açúcar), aminoácidos (gérmen de trigo e levedo de cerveja), vitaminas e sais minerais (complexo vitamínico). Entretanto, conforme o autor, a qualidade dos ingredientes de diferentes lotes pode afetar o valor nutritivo da dieta e, consequentemente, o desenvolvimento dos insetos que a consomem.

A qualidade da dieta das larvas também pode ter influência no desenvolvimento dos adultos. JOACHIMBravo; Zucoloto (1998) compararam larvas de C. capitata, oriundas de laboratório, alimentadas com dieta artificial ou mamão papaia $\left(29 \pm 1^{\circ} \mathrm{C}, 70 \%\right.$ U.R.). Os autores relataram que adultos originados de larvas de laboratório, quando alimentados com mamão na fase jovem, tornaram-se menores que os originados de larvas mantidas com dieta artificial. No presente estudo, as larvas de laboratório se desenvolveram em mamão papaia, diferentemente daquelas capturadas a campo, o que pode ter interferido no tamanho do ovário das moscas.

Outro fator que pode ter influenciado o menor tamanho dos órgãos reprodutivos das fêmeas em laboratório é o fato dela não receber indivíduos selvagens há três gerações. JOACHIM-Bravo et al. (2009) discutiram as modificações físicas e de comportamento de indivíduos de C. capitata criados em laboratório por muitas gerações. Os autores sugeriram que populações híbridas, com a introdução de moscas selvagens, periodicamente, evidenciam melhora na performance dos indivíduos.

Nas coletas realizadas no pomar de pessegueiros, no total, 43,3\% das fêmeas estavam maduras, 16,3\% em desenvolvimento e $40,4 \%$ imaturas. Esta proporção, entretanto, variou entre as diferentes ocasiões de coleta.

A presença de moscas imaturas sexualmente, mesmo durante a fase de pós-colheita, sugere que há mais de uma geração por safra, corroborando os resultados de SALLES (1995), o qual constatou quea espécie é multivoltina, estando os picos populacionais relacionados a outros hospedeiros multiplicadores.

No pomar de goiabeiras, a proporção de fêmeas maduras foi maior que no de pessegueiros, totalizando $67,8 \%$ das moscas capturadas, sendo que $22,6 \%$ eram imaturas e somente $9,7 \%$ estavam em desenvolvimento. Da mesma forma que no pomar de pessegueiros, houve grande variação na proporção das fêmeas em diferentes estágios de desenvolvimento em relação ao estágio dos frutos.

Nas fases de fruto verde e em maturação, a presença de moscas imaturas, foi praticamente inexistente, indicando que as fêmeas capturadas, em desenvolvimento oujá maduras, migraram de outras frutíferas para o pomar de goiabeiras. Observa-se que, na fase de fruto maduro, houve um aumento de captura de fêmeas imaturas, indicando uma segunda geração, que deve ter se desenvolvido nos frutos do próprio pomar.

O padrão de flutuação de fêmeas de $A$. fraterculus, nos estágios reprodutivos, imaturo e maduro, foi diferente entre os pomares (Fig. 2). No pomar de pessegueiros, os picos populacionais de fêmeas imaturas registrados podem caracterizar o recrutamento de indivíduos de três gerações. No final da colheita cresce o número de fêmeas maduras capturadas, que possivelmente ainda não haviam deixado o pomar em busca de outras frutíferas para a oviposição.

No pomar de goiabeiras, desdea primeira ocasião de amostragem, quando os frutos ainda estavam verdes, capturou-se um maior número de fêmeas maduras, sugerindo que elas tenham migrado de outros hospedeiros presentes nas áreas vizinhas. O número de fêmeas maduras capturadas foi mais elevado e manteve-se mais uniforme que no pomar de pessegueiros, entretanto, este decaiu no final das coletas, quando a maioria dos frutos havia caído das plantas. Por outro lado, as fêmeas imaturas começaram a ser capturadas somente quando os frutos entraram em maturação e, na última coleta, apresentaram o maior pico. A partir desta época, possivelmente estas fêmeas iriam migrar para áreas onde houvesse frutos nativos de final de verão, como a goiaba-serrana, que é a última mirtácea nativa a frutificar antes do inverno e na qual a infestação por mosca-das-frutas chega a 63\% (PEREIRA-RÊGO, 2010).

Trabalhos como os de SALLes (1995) e MACHADO et al. (1995) sugeriram que espécies de Anastrepha nas condições do sul do Brasil podem ter até seis gerações anuais. Através da dissecação e do registro de fêmeas imaturas nas diferentes fases de maturação dos frutos nos pomares, foi possível determinar que mais de duas gerações de moscas-das-frutas podem ocorrer nos pomares de pessegueiros região de Porto Alegre, em uma mesma safra. Este dado contrapõe o trabalho de SALLES (1998b) que sugeriu que $A$. fraterculus tem apenas uma geração por safra na cultura do pessegueiro.

Experimentos com coletas de moscas em fruteiras nativas, próximas aos pomares estudados e em épocas diferentes da safra, poderiam esclarecer as relações entre a maturação sexual das moscas 
e a atratividade destas para os pomares no início da cultura. As medições e descrições dos ovários respondem perguntas pertinentes ao controle de pragas, uma vez que são capazes de definir a época de aparecimento de novas gerações no campo.

\section{REFERÊNCIAS}

AYRES, M.; AYRES JUNIOR, M.; AYRES, D.L.; SANTOS, A.S.dos BioEstat 4.0 Aplicações estatísticas nas áreas da ciências biológicas e médicas. Belém: Sociedade Civil Mamirauá; Brasília: CNPq, 2006. 324p.

BARTOLUCCI, A.; VERA, M.T.; YUSEF, V.; OVIEDO, A. Morphological characterization of the reproductive system of irradiated Anastrepha fraterculus. Fruit Flies of Economic Importance: From Basic to Applied Knowledge. In: INTERNATIONAL SYMPOSIUM ON FRUIT FLIES OF ECONOMIC IMPORTANCE, 7., Salvador, 2006. Proceedings. Salvador, 2006. p.45-52.

BOTTON, M.; GRUTZMACHER, A.D.; MONTEIRO, L.B.; BAVARESCO, A. ARIOLI, C.J. Recomendações para o monitoramento da mosca-das-frutas sul americana e da mariposa oriental na produção integrada do pêssego. Pelotas: Embrapa, 2005. (Circular Técnica, 1).

BRESSAN, S. Desenvolvimento e potencial reprodutivo das fêmeas de Anastrepha obliqua (Macquart, 1835) (Diptera, Tephritidae) em condições naturais. Revista Brasileira de Entomologia, v.20, n.1, p.11-16, 1996.

CRUZ, I.B.M.; NASCIMENTO, J.C. do; TAUFER, M.; OLIVEIRA, A.K. Morfologia do aparelho reprodutor e biologia do desenvolvimento. In: MALAVASI, A.; ZUCCHI, R.A. (Ed.). Moscas-das-frutas de importância econômica no Brasil: conhecimento básico e aplicado. Ribeirão Preto: Holos, 2000. cap 6, p.55-66.

GATELLI, T.; SILVA, F.F.; MEIRELLES, R.N.; REDAELLI, L.R.; SOGLIO, F.K. Dal. Moscas frugívoras associadas a mirtáceas e laranjeira "Céu" na região do Vale do Rio Caí, Rio Grande do Sul, Brasil. Ciência Rural, v.38, n.1, p.236-239, 2008

JALDO, H.E.; GRAMAJO, M.C.; WILLINK, E. Mass rearing of Anastrepha fraterculus (Diptera:Tephritidae): a preliminary strategy. Florida Entomology, v.84, n.4, p.716-718, 2001.

JOACHIM-BRAVO, I.S.J.; ZUCOLOTO, F.S. Performance and feeding behavior of Ceratitis capitata: camparison of a wild population and laboratory population. Entomologia Experimentalis et Applicata, v.87, p.67-72, 1998.

JOACHIM-BRAVO, I.S.J.; SILVA NETO, A.M.; DIAS, V.S. Biological and behavioral aspects of two laboratory strains of Ceratitis capitata (Diptera: Tephritidae): the influence of periodic introduction of wild flies in the colony. Acta Zoologica Mexicana, v.22, n.2, p.359-374, 2009.
KOVALESKI, A.; SUGAYAMA, R.L.; MALAVASI, A. Movement of Anastrepha fraterculus from native breeding sites into Apple orchards in Southern Brazil. Entomologia Experimentalis et Applicata, v.91, p.457-463, 1999.

LEAL, M.R.; SOUZA, S.A.S.; AGRUIAR-MENEZES, E.L.; LIMA FILHO, M.; MENEZES, E.B. Diversidade de moscas-das-frutas, suas plantas hospedeiras e seus parasitóides nas regiões Norte e Nordeste do Estado do Rio de Janeiro, Brasil. Ciência Rural, v.39, n.3, p.627-634, 2009.

MACHADO, A.E.; SALLES, L.A.B.; LOECK, A.E. Exigências térmicas de Anastrepha fraterculus (Wied.) e estimativa do número de gerações anuais em Pelotas, RS. Anais da Sociedade Entomológica do Brasil, v.24, n.3, p.573-578, 1995

MARTINEZ, I.M.; ORTIZ, V.H. Anatomy of the reproductive system in six Anastrepha species and comments regarding their terminology in Tephritidae (Diptera). Proceedings of the Entomological Society of Washington, v.99, n.4, p.727-743, 1997.

MARTINEZ, I.M.; ORTIZ, V.H.; LUNA, R.L. Desarrolo y maduracion sexual em Anastrepha serpentina (Wiedemann) (Diptera: Tephritidae). Acta Zoologica Mexicana, v.65, p.75-88, 1995.

MORGANTE, J.S. Moscas-das-frutas (Tephritidae): características biológicas, detecção e controle. Brasília: SENIR, 1991. 19p. (Boletim Técnico, 2).

PEREIRA-RÊGO, D.R.G. Mosca-das-frutas sul-americana, Anastrepha fraterculus (Wied.) (Diptera: Tephritidae) $e$ parasitóides associados: infestação, parasitismo e distribuição espacial em mirtáceas nativas, no Rio Grande do Sul. 2010. 72p. Dissertação (Mestrado em Fitotecnia) - Faculdade de Agronomia, Universidade Federal do Rio Grande do Sul, Porto Alegre, 2010.

PEREIRA-RÊGO, D.R.G.; JAHNKE, S.M.; REDAELLI, L.R.; SCHAFFER, N. Morfometria de Anastrepha fraterculus (Wied) (Diptera: Tephritidae) relacionada a hospedeiros nativos, Myrtaceae. Arquivos do Instituto Biológico, São Paulo, v.78, n.1, p.37-43, 2011.

PRITCHARD, G. The ecology of a natural population of the Queensland fruit fly, Dacus tryoni. III. The maturation of female flies in relation to temperature. Australian Journal of Zoology, v.18, p.77-89, 1970.

SALLES, L.A.B. Metodologia de criação de Anastrepha fraterculus (Wied., 1830) (Diptera: Tephritidae) em dieta artificial em laboratório. Anais da Sociedade Entomologica do Brasil, v.21, n.3, p.479-486, 1992.

SALLES, L.A.B. Influência do fotoperíodo no desenvolvimento de Anastrepha fraterculus (Wied. 1830) (Diptera: Tephritidae). Anais da Sociedade Entomológica do Brasil, v.22, n.1, p.63-69, 1993. 
SALLES, L.A.B. Bioecologia e controle da mosca-das-frutas sul-americana. Pelotas: EMBRAPA- CPACT, 1995.

$58 \mathrm{p}$.

SALLES, L.A.B. Behaviour of Anastrepha fraterculus. The south American fruit fly, Anastrepha fraterculus (Wied); advances in artificial rearing, taxonomic status and biological studies. Vienna: IAEA, 1998a.

SALLES, L.A.B. Principais pragas e seu controle. In: MEDEIROS, C.A.; RASEIRA, M.C. (Ed.). A cultura do pessegueiro. Brasília: Embrapa, 1998b. p.205-242.

SALLES, L.A.B. Biologia e ciclo de vida de Anastrepha fraterculus (Wied.). In: MALAVASI, A.; ZUCCHI, R.A. (Ed.). Moscas-das-frutas de importância econômica no Brasil: conhecimento básico e aplicado. Ribeirão Preto: Holos, 2000. cap 8, p.81-86.

SILVA, F.F. MEIRELLES, R.N.; REDAELLI, L.R.; SOGLIO, F.K. Dal. Diversity of flies (Diptera: Tephritidae and Lonchaeidae) in organic citrus orchards in the Vale do Rio Caí, Rio Grande do Sul, Southern Brazil. Neotropical Entomology, v.35, n.5, p.666-670, 2006.

SOUZA, J.C.; RAGA, A.; SOUZA, M.A. Pragas da goiabeira. Belo Horizonte: EPAMIG, 2003. 60p. (Boletim Técnico, 71).
TAUFER, M.; NASCIMENTO, J.C.; CRUZ, I.B.M.; OLIVEIRA, A.K. Efeito da temperatura na maturação ovariana e longevidade de Anastrepha fraterculus (Wied.) (Diptera: Tephritidae). Anais da Sociedade Entomologica do Brasil, v.29, n.4, p.639-648, 2000.

TAYLOR, P.W.; YUVAL, B. Postcopulatory sexual selection in Mediterranean fruit flies: advantages for large and protein-fed males. Animal Behaviour, v.58, p.247254, 1999.

WILLIAMSON, D.L. Oogenesis and spermatogenesis. In: ROBINSON A.S.; HOOPER, G. (Ed.). Fruit flies. Their biology, natural enemies and control. Amsterdam: Elsevier, 1989. v.3A, p.141-151.

ZUCCHI, R.A. Taxonomia. In: MALAVASI, A.; ZUCCHI, R.A. (Ed.). Moscas-das-frutas de importância econômica no Brasil: conhecimento básico e aplicado. Ribeirão Preto: Holos, 2000. chap 1, p.13-24.

ZUCOLOTO, F.S. Nutrição e alimentação, In: MALAVASI, A.; ZUCCHI, R.A. (Ed.). Moscas-das-frutas de importância econômica no Brasil: conhecimento básico e aplicado. Ribeirão Preto, Holos, 2000. p.67-80.

Recebido em 22/2/11

Aceito em 3/5/12 